\title{
Academic Doctorate Degree Completion
}

National Cancer Institute

\section{Source}

National Cancer Institute. Academic Doctorate Degree Completion. NCI Thesaurus. Code C70557.

Indicates that a person has received a degree for completion of the highest award earned for graduate study. 